\title{
Triple Ion-Beam Studies of Radiation Damage in 9Cr2WVTa Ferritic/Martensitic Steel for a High Power Spallation Neutron Source
}

\author{
E. H. Lee, J. D. Hunn, G. R. Rao, R. L. Klueh, and L. K. Mansur \\ Metals and Ceramics Division, Oak Ridge National Laboratory, P.O. Box 2008 \\ Oak Ridge, TN 37831-6376, USA
}

To simulate radiation damage under a future Spallation Neutron Source (SNS) environment, irradiation experiments were conducted on a candidate 9Cr-2WVTa ferritic/martensitic steel using the Triple Ion Facility (TIF) at ORNL. Irradiation was conducted in single, dual, and triple ion beam modes using $3.5 \mathrm{MeV} \mathrm{Fe}^{++}, 360 \mathrm{keV} \mathrm{He}^{+}$, and $180 \mathrm{keV} \mathrm{H}^{+}$at 80,200 , and $350{ }^{\circ} \mathrm{C}$. These irradiations produced various defects comprising black dots, dislocation loops, line dislocations, and gas bubbles, which led to hardening. The largest increase in hardness, over $63 \%$, was observed after 50 dpa for triple beam irradiation conditions, revealing that both $\mathrm{He}$ and $\mathrm{H}$ are augmenting the hardening. Hardness increased less than $30 \%$ after $30 \mathrm{dpa}$ at $200{ }^{\circ} \mathrm{C}$ by triple beams, compatible with neutron irradiation data from previous work which showed about a $30 \%$ increase in yield strength after $27.2 \mathrm{dpa}$ at $365^{\circ} \mathrm{C}$. However, the very large concentrations of gas bubbles in the matrix and on lath and grain boundaries after these simulated SNS irradiations make predictions of fracture behavior from fission reactor irradiations to spallation target conditions inadvisable. Keywords: First wall materials, Helium, Hydrogen, Ion irradiation, Radiation effects, Ferritic steel

\footnotetext{
*Research sponsored by the Division of Materials Sciences, U.S. Department of Energy under contract number DE-AC05-96OR22464 with Lockheed Martin Energy Research Corporation.
} 


\section{Introduction}

Austenitic and ferritic steels are potential candidate alloys for structural materials for the Spallation Neutron Source (SNS). In an earlier paper [1], the results for accelerator-irradiated $316 \mathrm{LN}$ austenitic steel were reported. This paper summarizes the results for $9 \mathrm{Cr}-2 \mathrm{WVTa}$ ferritic/martensitic steel. This reduced-activation steel was chosen for investigation because of its excellent response to neutron irradiation compared with conventional Cr-Mo steels [2]. The major weakness of ferritic steels is that irradiation affects toughness by causing a large increase in ductile-brittle transition temperature (DBTT) and decrease in upper-shelf energy (USE) in a Charpy impact test. The 9Cr-2WVTa alloy was developed as a reduced-activation steel in the U.S. fusion program, in which $\mathrm{Mo}$ and $\mathrm{Nb}$ in conventional Cr-Mo steels were replaced with $\mathrm{W}$ and Ta, respectively $[3,4]$. Substantial data have been generated for this alloy subjected to fission neutron irradiation [2], but none for the SNS condition. However, information on radiation damage effects in the SNS environment is urgently needed for design purposes. Under the SNS environment, damage may be worse than in fission reactors due to the very high energy protons $(1 \mathrm{GeV})$, neutrons with energies from the proton energy down to thermal energies, and high concentrations of transmutation products, particularly hydrogen and helium. In an effort to obtain materials performance data in such a severe irradiation environment, experiments were carried out using the Triple Ion Facility (TIF) at ORNL. The TIF was used because it can simulate the gas/dpa ratios expected in the SNS environment.

\section{Experimental}

Transmission electron microscopy (TEM) specimen disks were prepared from Heat No. 3791 of the 9 Cr-2WVTa ferritic/martensitic steel. Nominal alloy composition is Fe-9Cr-2W$0.25 \mathrm{~V}-0.12 \mathrm{Ta}-0.1 \mathrm{C}$ in weight percent [2]. Disk specimens were austenized $0.5 \mathrm{~h}$ at $1050{ }^{\circ} \mathrm{C}$ 
under flowing helium followed by a fast inert gas cool and tempered $1 \mathrm{~h}$ at $750{ }^{\circ} \mathrm{C}$ followed by fast inert gas cool. Electrochemically polished disks were irradiated at 80,200 , and $350^{\circ} \mathrm{C}$ in single, dual, and triple beam modes using $3.5 \mathrm{MeV} \mathrm{Fe}^{++}, 360 \mathrm{keV} \mathrm{He}^{+}$, and $180 \mathrm{keV} \mathrm{H}^{+}$. Details regarding the triple ion beam facility can be found in Ref. [5] and additional information regarding this experimental effort can be found in the previous paper on austenitic steel [1]. The ion energies were chosen to maximize the damage and the gas accumulation at the same depth of $\sim 1 \mu \mathrm{m}$ by using the Monte Carlo simulation code, the Stopping and Range of Ions in Matter (SRIM, 1996 version, formerly known as TRIM) [6]. Although the SNS is expected to operate with an atomic displacement rate of up to $\sim 10^{-2} \mathrm{dpa} / \mathrm{s}$ in a pulsed mode with a microsecond beam duration at a $10-60 \mathrm{~Hz}$ pulse frequency, in this work $\mathrm{Fe}^{++}$ion irradiations were carried out in a non-pulsed mode with $1 \times 10^{-3}$ to $3 \times 10^{-3} \mathrm{dpa} / \mathrm{s}$ damage rate. Helium and hydrogen injection rates were $~ 200 \mathrm{appm} \mathrm{He/dpa} \mathrm{(0.5-1.5} \mathrm{appm} \mathrm{He/s)} \mathrm{and} 1000 \mathrm{appm} \mathrm{H/dpa} \mathrm{(3-8} \mathrm{appm} \mathrm{H/s),}$ respectively, which correspond with the gas/dpa rates expected in the SNS. For most irradiations, the accumulated $\mathrm{Fe}^{++}$ion dose was $50 \mathrm{dpa}\left(5 \times 10^{20}\right.$ ions $\left./ \mathrm{m}^{2}\right)$, and corresponding $\mathrm{He}$ and $\mathrm{H}$ gas concentration levels at the peak deposition range were 10,000 appm $\left(3.5 \times 10^{20}\right.$ ions $\left./ \mathrm{m}^{2}\right)$, and 50,000 appm $\left(1.4 \times 10^{21}\right.$ ions $\left./ \mathrm{m}^{2}\right)$, respectively. For a Fe ${ }^{++}$dose of $50 \mathrm{dpa}$, the displacement contributions by $\mathrm{He}$ and $\mathrm{H}$ were 0.9 and 0.3 dpa, respectively. To investigate the dose dependence of hardness change, specimens were also irradiated at $200{ }^{\circ} \mathrm{C}$ to doses of $0.1,1$, 10, 30, 40 50, and 80 dpa with triple ion beams using the same $\mathrm{He}$ and $\mathrm{H}$ injection rates. Variation in microstructure and hardness of irradiated specimens was studied using transmission electron microscopy (TEM) and a nanoindentation technique. TEM specimens were prepared by electrochemically removing a $600-700 \mathrm{~nm}$ surface layer from the ion bombarded side and backthinning from the unirradiated side until perforation, such that the 
perforation was close to the peak damage region. The thinned specimens were examined in a Phillips CM-12 electron microscope operated at $120 \mathrm{KV}$. Hardness changes were measured using a nanohardness tester with a pyramidal Berkovich indenter. Hardness data were obtained as a function of indentation depth up to $700 \mathrm{~nm}$. Since the indentation strain field extends over about 7 times the indentation depth, the effect of the underlying unirradiated substrate becomes significant as the indenter approaches the depth of the ion range. At shallow surface depths less than $50 \mathrm{~nm}$, measured hardness values are unreliable because of uncertainties in the indenter tip geometry and because of surface artifacts, such as an oxide layer, surface roughness, and polishing defects. For these reasons, the data tended to scatter considerably from indent to indent at less than $100 \mathrm{~nm}$ indentation depth. Therefore, the hardness values at $200 \mathrm{~nm}$ indentation depth were used for comparison to minimize the surface and substrate effects. Detailed consideration for the choice of $200 \mathrm{~nm}$ as a reference depth was reported previously [1]. The general procedure used for the nanoindentation technique can be found elsewhere $[7,8]$.

\section{Results}

TEM examination revealed that the unirradiated specimen had a typical normalized-andtempered martensite structure characterized by various sizes of laths with varying high dislocation densities. Dislocation density varied from lath to lath in the range of $10^{14}-10^{15}$ $\mathrm{m} / \mathrm{m}^{3}$. Major precipitate phases were large $\left(\sim 100 \mathrm{~nm}\right.$ in diameter) $\mathrm{M}_{23} \mathrm{C}_{6}$ and smaller MC particles, precipitates often being found at lath boundaries. These observations are consistent with previous reports $[3,4]$.

Although various defects comprising black dots, faulted and unfaulted loops, and line dislocations were seen in all irradiated specimens, the defect structures were obscured by the complex strain contrast arising from the pre-existing high density dislocations, cell structures, 
lath boundaries, and precipitates. Very little recovery of the pre-existing microstructural features seemed to occur during irradiation at these low temperatures $\left(80-350{ }^{\circ} \mathrm{C}\right)$. Moreover, defects produced at these low irradiation temperatures were small in size, typically less than a few nm. Formation of a very high number density of fine bubbles was apparent in all He- and/or H-injected specimens. Randomly distributed, large bubbles were found occasionally, but most bubbles were too small, less than $1 \mathrm{~nm}$ in diameter, to be imaged with clarity within the TEM resolution limit. For this reason, no quantitative measurement could be made for the radiationinduced loops, dislocations, and bubbles. Significantly, however, clearly visible large bubbles ( $6 \mathrm{~nm}$ in diameter) were observed at dislocations with poorly defined small bubbles $(<1 \mathrm{~nm})$ in the matrix. A bimodal cavity size distribution was observed for the specimen triple beam irradiated to $50 \mathrm{dpa}$ at $80{ }^{\circ} \mathrm{C}$, but not for those irradiated at 200 and $350{ }^{\circ} \mathrm{C}$. Typical TEM microstructures for unirradiated and triple beam irradiated specimens are displayed in Fig. 1.

Figure 2 shows hardness variation as a function of indentation depth for the specimens irradiated to 50 dpa at $80{ }^{\circ} \mathrm{C}$ with triple, dual, and single ion beams. There was some scatter ( $\pm 0.5 \mathrm{GPa}$ ) in hardness measurements from indent to indent, particularly at shallow indentation depths, mainly due to the nonuniform lath structure with varying dislocation density in the normalized and tempered martensitic steel. As mentioned already, hardness values at a $200 \mathrm{~nm}$ indentation depth were used for comparison, and hereafter, all hardness values referred to in the text are at a $200 \mathrm{~nm}$ depth. Figure 3 compares the hardness values at $200 \mathrm{~nm}$ indentation depth as a function of temperature for specimens irradiated to 50 dpa by single, dual, and triple beams.

The hardness of the unirradiated steel was about $3.35 \mathrm{GPa}$. The largest measured hardness was $6.3 \pm 0.5 \mathrm{GPa}$ for the triple beam irradiation to $50 \mathrm{dpa}$ at $350{ }^{\circ} \mathrm{C}$. Overall data 
showed that triple beams produced the largest hardening, followed by $\mathrm{Fe}+\mathrm{He}, \mathrm{Fe}, \mathrm{Fe}+\mathrm{H}, \mathrm{He}$, $\mathrm{He}+\mathrm{H}$, and $\mathrm{H}$ beams. In general, helium enhanced hardening both in triple and $\mathrm{Fe}+\mathrm{He}$ dual beam modes, particularly at $200{ }^{\circ} \mathrm{C}$. On the other hand, above $200{ }^{\circ} \mathrm{C}$, hydrogen reduced hardening in the dual beam mode compared to single Fe irradiation but increased hardening above that for $\mathrm{Fe}+\mathrm{He}$ dual beams in triple beam mode. A single He beam caused substantial hardening, while a single $\mathrm{H}$ beam caused virtually no change in hardness from the unirradiated value except at $80{ }^{\circ} \mathrm{C}$. Hardening tended to increase with increasing irradiation temperature when the Fe beam was employed, singly or together with He and/or H.

Figure 4 (top) shows the dose dependence of hardness for triple beam irradiatiation at $200{ }^{\circ} \mathrm{C}$. For comparison, the yield strength changes are also shown in the figure for the same alloy neutron irradiated in Fast Flux Test Facility (FFTF). There was no discernible change in hardness after 0.1 dpa. A slight increase ( 10\%) was indicated up to 10 dpa. At 30 and 40 dpa, hardness had increased about $25 \%$ to $\sim 4.2 \mathrm{GPa}$. Hardness values showed a large jump, over 63 $\%$ to $\sim 5.5 \mathrm{GPa}$, after $50 \mathrm{dpa}$. With increasing dose to $80 \mathrm{dpa}$, hardness declined to $\sim 5 \mathrm{GPa}$, indicating that perhaps some recovery of dislocation structure might be occurring during irradiation, especially at the higher doses.

\section{Discussion}

TEM examination revealed that the microstructure of the normalized-and-tempered martensitic steel had a complex dislocation and cell structure, which made quantitative characterization of irradiation-induced defects very difficult, as seen in Fig. 1. For this reason, although radiation-induced defects such as black dots, loops, and bubbles are known to lead to hardening [9-14], no quantitive correlation could be made between microstructure and mechanical property changes. 
Of particular interest was the appearance of a bimodal cavity size distribution for the 80 ${ }^{\circ} \mathrm{C}$ triple beam irradiation. A similar observation was made for the austenitic $316 \mathrm{LN}$ steel irradiated with triple beams at $80{ }^{\circ} \mathrm{C}$ [1]. In the previous theoretical analysis [1], the appearance of the bimodal cavity size distribution at $80{ }^{\circ} \mathrm{C}$ was attributed to a smaller critical cavity size at this low temperature. Although bias-driven cavity growth is expected at the SNS operating temperature range, cavity swelling is not expected to impose any serious problem for the SNS target materials because the cavity growth rate is extremely small at low temperatures.

Hardness data showed that the predominant cause of radiation hardening was displacement damage by the Fe-beam irradiation. While a single He-beam increased hardening at all three irradiation temperatures, the effect of a single H-beam irradiation was rather small. However, when $\mathrm{He}$ and $\mathrm{H}$ were injected simultaneously with $\mathrm{Fe}$, hardening was augmented, such that the most severe hardening occurred with triple beams. These results suggest that hardening of this material under SNS conditions would be worse than those under fission or future fusion neutron irradiations at a comparable dose level.

At this time, there are some tensile data for Fe, Ta, Fe-2Cr-1Mo, and Fe-12Cr-1Mo (HT9) steels irradiated by $800 \mathrm{MeV}$ protons at the Los Alamos Meson Physics Facility (LAMPF) [15] but no data is available for 9Cr-2WVTa alloy for SNS conditions. However, Fast Flux Test Facility (FFTF) neutron-irradiation data indicated that 9Cr-2WVTa steel showed by far the best performance among a range of ferritic steels [2]. The yield strength increased by $31 \%$ from 544 MPa to $710 \mathrm{MPa}$ after irradiation to $27.2 \mathrm{dpa}$ at $365^{\circ} \mathrm{C}$. The DBTT increased only $32{ }^{\circ} \mathrm{C}$, from 88 to $-56{ }^{\circ} \mathrm{C}$ and the upper-shelf energy (USE) decreased by $28 \%$, from $11.2 \mathrm{~J}$ to $8.1 \mathrm{~J}$. This represents a considerable improvement over conventional Cr-Mo Steels [2]. Figure 4 (bottom) shows that both hardness and yield strength increased by a similar amount, $\sim 30 \%$ after $\sim 30$ dpa. 
Although the yield strength and DBTT increased continuously with increasing dose, there was no significant loss of impact toughness up to $27.2 \mathrm{dpa}$ at $365^{\circ} \mathrm{C}$ in FFTF. If one could associate the neutron data for all mechanical properties measured to ion data for hardness only, then this steel irradiated under SNS conditions might be used for a lifetime of up to 30 dpa. However, this cannot be done in general, especially in this case, since the lifetime may be shortened considerably due to the high helium and hydrogen concentrations, 200 He appm per dpa and $\sim 1000 \mathrm{H}$ appm per dpa in SNS compared to $\sim 0.1 \mathrm{He}$ appm per dpa and insignificant $\mathrm{H}$ generation in FFTF.

For an $\mathrm{Fe}^{++}$dose of $50 \mathrm{dpa}$, the displacement damage levels by helium and hydrogen are only 0.9 and $0.3 \mathrm{dpa}$, respectively. Additional hardening by $\mathrm{He}$ and $\mathrm{H}$ could be due to direct dislocation pinning by gas bubbles $[10,14]$ and due to dislocation loops produced by punching from over-pressurized bubbles [12] and by excess interstitials left by the process of gas atomvacancy clustering [13]. The detailed relationship between hardening and the $\mathrm{He}$ and $\mathrm{H}$ transmutation products is not known, but it is clear that the gases accelerate hardening. Possible embrittlement effects caused by hydrogen and helium have not been studied in this work. Such embrittlement is likely to arise from two sources; hardening and the lath/grain boundary bubbles. Hydrogen embrittlement is not thought to be a problem in fusion reactor materials when operating above $215^{\circ} \mathrm{C}$ for a hydrogen generation rate of $6 \times 10^{-7} \mathrm{wppm} / \mathrm{s}$. Under these conditions, hydrogen should diffuse from the steel and not build up to the threshold amount required to cause embrittlement [16]. The lower temperature and higher hydrogen generation rates of the SNS and the presence of a considerable concentration of helium bubbles may lead to more hydrogen retention. Helium effects have been studied in mixed-spectrum reactors where it is possible to generate transmutation helium by the interaction of nickel with thermal neutrons 
[17]. Neutron irradiation of nickel-doped modified 9Cr-1Mo and Sandvik HT-9 steels in the High Flux Isotopes Reactor indicated that helium may cause an increase in DBTT beyond that caused by displacement damage alone [17]. More work is required to determine whether hydrogen and helium embrittlement will occur under SNS conditions. Moreover, substantial amounts of other inert gas atoms such as Ar and Ne will be also generated in the SNS, whose effects are not known at this time.

Hardness showed an increasing trend with dose, peaking at 50 dpa, Fig. 4. Data by Camus et al. [18] indicated that hardness saturation occurred near 25 dpa for ferritic steels irradiated by $300 \mathrm{keV} \mathrm{Fe}$ and $150 \mathrm{keV} \mathrm{He}^{+}$dual beams with 200 appm/dpa helium injection rate. In their work, the implantation depth was very shallow, about $150 \mathrm{~nm}$, due to the low ion energies, and thus there was a considerable scatter in the hardness data. Their hardness data showed virtually no temperature dependence between 113 to $400{ }^{\circ} \mathrm{C}$ at all doses. In the present work, a substantial increase in hardness was observed with increasing irradiation temperature when the Fe beam was employed. However, the temperature dependency is not considered to be a critical issue, since the present data also showed only mild temperature dependency below 200 ${ }^{\circ} \mathrm{C}$, and the SNS would be operated below $200{ }^{\circ} \mathrm{C}$.

\section{Conclusions}

In an effort to investigate materials performance under the SNS environment, 9Cr2WVTa steel specimens were irradiated using the triple ion facility (TIF) at ORNL. Irradiations were conducted at 80,200 , and $350{ }^{\circ} \mathrm{C}$ in single, dual, and triple ion beam modes with $3.5 \mathrm{MeV}$ $\mathrm{Fe}^{++}, 360 \mathrm{keV} \mathrm{He}$, and $180 \mathrm{keV} \mathrm{H}$. Helium and hydrogen injection rates were 200 appm He/dpa and $~ 1000$ appm H/dpa, respectively.

Since bimodal cavity size distribution was observed for $80{ }^{\circ} \mathrm{C}$ irradiation, bias-driven 
cavity growth may occur in the SNS target materials. However, cavity swelling is not considered to be a problem because the cavity growth rate is insignificant within the expected SNS operating temperature ranges.

Hardness measurements revealed that the triple ion beam irradiation produced the most severe hardening, followed by $\mathrm{Fe}+\mathrm{He}, \mathrm{Fe}, \mathrm{Fe}+\mathrm{H}, \mathrm{He}$, and $\mathrm{He}+\mathrm{H}$ beams. Hydrogen alone produced virtually no hardening at all temperatures, but its synergistic effect was quite evident, particularly at $350{ }^{\circ} \mathrm{C}$. Hardness increases were similar to yield strength increases after neutron irradiation, $\sim 30 \%$ after $\sim 30 \mathrm{dpa}$. The presence of gas bubbles, especially those on lath and grain boundaries, raises concerns about interfacial weakening.

\section{Acknowledgments}

This research was sponsored by the Division of Materials Sciences, U.S. Department of Energy, under contract No. DE-AC05-96OR22464 with Lockheed Martin Energy Research Corporation. The authors would like to thank Dr. M. B. Lewis and Mr. S. W. Cook for assisting accelerator irradiation, and Drs. K. Farrell and R. E. Stoller for technical review of the manuscript. 


\section{References}

1. E. H. Lee, G. R. Rao, J. D. Hunn, P. M. Rice, M. B. Lewis, S. W. Cook, K. Farrell, and L. K. Mansur, Proc. TMS Symp. on Materials for Spallation Neutron Sources, ed M. S. Wechsler, (Orlando, Florida, February, 1997)

2. R. L. Klueh and D. J. Alexander, Effects of Radiation on Materials: $18^{\text {th }}$ International Symposium, ASTM STP 1325, R. K. Nanstad, M. L. Hamilton, F. A. Garner, and A. S. Kumar, Eds., American Society for Testing and Materials, 1997.

3. $\quad$ R. L. Klueh and P. J. Maziasz, Met. Trans. 20A (1989) 373.

4. J. J. Kai and R. L Klueh, J. Nucl. Mater.230 (1996) 116.

5. M. B. Lewis, W. R. Allen, R. A. Buhl, N. H. Packan, S. W. Cook, and L. K. Mansur, Nucl. Instrum. Methods, B43 (1989) 243.

6. J. F. Ziegler, J. P. Biersack, and U. Littmark, "The Stopping and Range of Ions in Solids, Pergamon Press (1985).

7. W. C. Oliver and G. M. Pharr, J. Mater. Res., 7 (1992) 1564.

8. $\quad$ E. H. Lee, Y. Lee, W. C. Oliver, and L. K. Mansur, J. Mater. Res., 8 (1993) 377.

9. A. L. Bement, Jr., Proc. On the Strength of Metals and Alloys (ASM, Metals Park, 1970) 693.

10. R. E. Stoller, "Effects of Radiation on Materials," $16^{\text {th }}$ Int. Symp., ASTM STP 1175, A. S. Kumar, D. S. Gelles, R. K. Nanstad, and E. A. Little, Eds., American Society for Testing and Materials, Philadelphia (1993) 394.

11. M. L. Grossbeck, P. J. Maziasz, and R. F. Rowcliffe, J. Nucl. Mater., 191-194 (1992) 808.

12. H. Trinkaus, Radiation Effects, 78 (1983) 189. 
13. K. Farrell, R. W. Chickering, and L. K. Mansur, Phil. Mag. A, 53 (1986) 1.

14. E. H. Lee, N. H. Packan, M. B. Lewis,and L. K. Mansur, Nucl. Mater. Meth., B16 (1986) 25.

15. Robert D. Brown, Monroe S. Wechsler, and Christoph Tschalär, "Effect of Radiation on Materials Properties: $13^{\text {th }}$ International Symposium (Part II), ASTM STP 956, F. A. Garner, C. H. Henager, Jr., and N. Igata, Eds., American Society for Testing and Materials, Philadelphia, (1987) 131.

16. P. Jung, Fusion Technology, in press.

17. R. L. Klueh and D. J. Alexander, J. Nucl. Mater., 187 (1992) 60.

18. Camus et. al, Proc. TMS Symp. on Materials for Spallation Neutron Sources, ed. M. S. Wechsler, (Orlando, Florida, February, 1997). 
Figure Captions

Figure 1. TEM microstructures of unirradiated (a) and triple beam irradiated to 50 dpa at $80{ }^{\circ} \mathrm{C}(\mathrm{b})$. Other single and dual beam irradiated specimens also showed similar dislocation microstructure.

Figure 2. Hardness values as a function of indentation depth for 9Cr-2WVTa steel irradiated to $50 \mathrm{dpa}$ at $80^{\circ} \mathrm{C}$ for various irradiation beam modes.

Figure 3. Hardness values as a function of irradiation temperature for various irradiation modes.

Figure 4. Hardness and yield strength changes as a function of dose for triple beam and FFTF neutron irradiations, respectively (top) and corresponding percentage changes (bottom). 


